

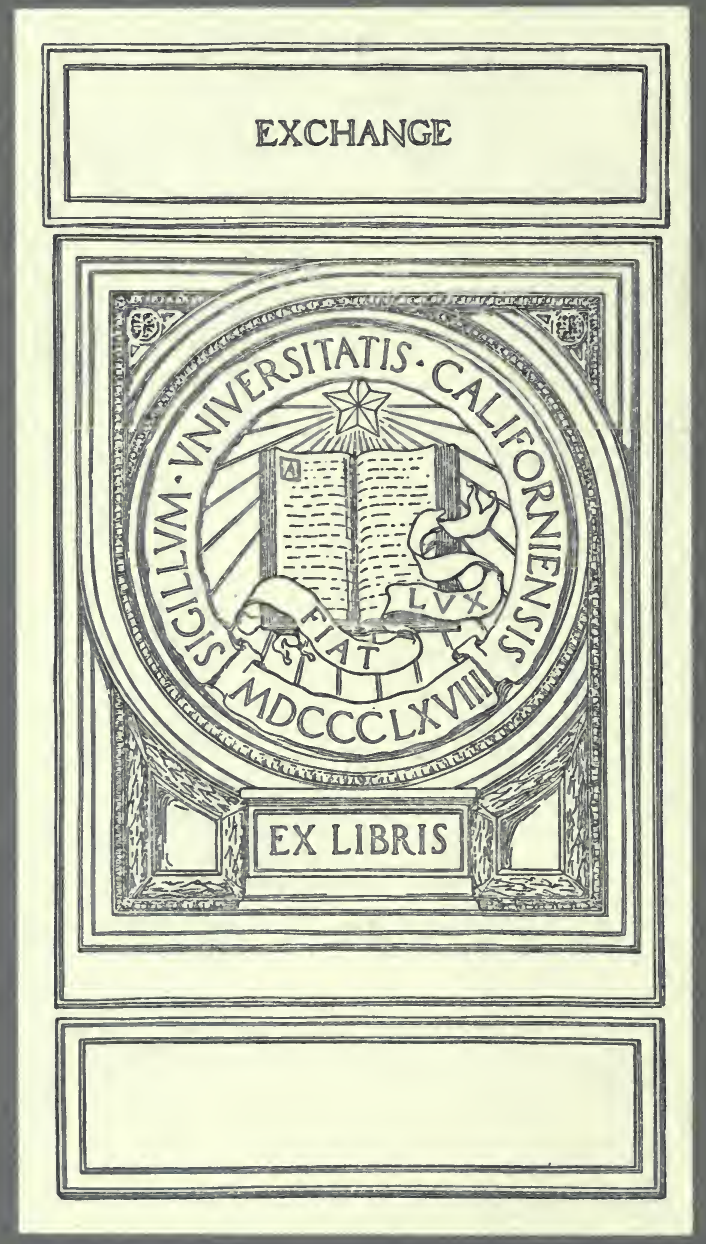



Digitized by the Internet Archive in 2007 with funding from Microsoft Corporation 


\section{STRAWBERRY GROWING.}

(Revised Edition.)

BULLETIN No. 21.

\section{DEPARTMENT OF AGRICULTURE $-\mathrm{OF}-$}

\section{BRITISH COLUMBIA.}

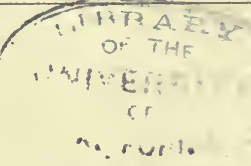


Bulletin No. 21, on Strawberry Growing, being a revised edition of No. 17, is published by direction of the Hon. R. G. Tatlow, Minister of Agriculture, for distribution amongst members of Farmers' Institutes and for general information.

\section{J. R. ANDERSON,}

Deputy Minister of Agriculture.

Department of Agriculture,

Victoria, B. C., 25th April, 190\%. 


\section{THE STRAWBERRY.}

THE production of this delicious fruit has of late assumed such proporI. tions and the enquiries as to its cultivation are so numerous that, in response to the frequent requests for information, it has been considered advisable to collect all important facts from various authorities and publish them in belletin form.

It is needless here to enter into the merits of the strawberry. It is considered the most wholesome of all fruits, being very easy of digestion and never growing acid by fermentation as most other fruits do. Downing says : "The oft-quoted instance of the great Linnæus curing himself of gout by partaking freely of strawberries-a proof of its great wholesomeness-is a letter of credit which this tempting fruit has long enjoyed, for the consolation of those who are looking for a bitter concealed under every sweet." It is not, however, on account so much of its qualities for home use as its value from a commercial standpoint, that the following pages are offered to the public of British Columbia. It is now an ascertained fact that the finest quality of strawberries can be and are grown in various parts of the Province. The markets of the North-West Territories, Manitoba and the northern mines afford such great opportunities for their profitable production that the advice given by the Honourable E. Hofer, in a paper read before the State Horticultural Society of Oregon, is well worth consideration. He says: "There is no trouble to grow large strawberries. 'The difficulty is rather to get varieties that are not too large-berries of medium size that average well, are of regular shape, either round or conical pointed fruit that looks well in the box ready for the retailer. Aroid growing large misshapen fruit. It is important to grow a variety that does not run out small after the first picking. For the home market grow a showy berry above medium size; but for shipment an entirely different proposition is involved. A berry may be a perfect success for the home market and endure hauling several miles and be entirely unfit for the express car or refrigerator for long distance shipment. A shipping berry should be solid, have a good skin and fine texture, be of medium size, of roundish pointed shape, and ripen several days after picking." Clarke's seedling, as grown at Hood River, Oregon, under irrigation and a crisp mountain atmosphere, has the ideal shipping qualities, but experience has proved that in this Province it is not a good producer. This fact goes to show that, just like any other fruit-apples, pears, peaches, plums, etc.it is not every variety which has been proved successful elsewhere that should necossarily be a profitable one in all parts of the Province. Bearing this in mind further on, I have given the answers of some of the successful provincial growers as to that and other points. The aspiring grower, if he would be successful, must bear in mind that, like growing apples and other fruit, he can only become so by patient concentration upon the fundamental 
principles and details of the business. Mr. Hofer concluded his paper as follows: "Co-operate with your neighbours; form a fruit-growers' union to secure a standard of quality for your section. That is a great secret of success, for having established a standard and maintaining it is the best advertisement of your crop and your neighbourhood."

It has been thought advisable to select excerpts from publications which are considered to be the best suited to our requirements and ionditions, which here follow. The experience of our own growers is given further on, and whilst in some minor points there may be differences of opinion, the fundamental principles governing the growing of plants is the sarue the world over, and applies to the cultivation of strawberries equally with other plants. It will be observed that the concensus of opinion of local growers is decidedly in favour of the Magoon; for the local market, in a minur degree, and for transhipment, overwhelmingly so. Opinions also as to the best system of planting are altogether in favour of that known as the hill system.

As will be seen, the recommendations regarding the distances at which strawberries should be planted in this Province vary considerably, the closest being rows 32 inches apart and from 10 to 12 inches in the rows; the greatest distance being rows 3 feet 6 inches apart and 18 inches in the rows. A good average distance is probably rows 3 feet apart and 15 to 18 inches in the rows. By the Central Experimental Farm Bulletin No. 5, rows 2 feet apart and 12 to 15 inches in the rows is recommended; and in Michigan, rows 2 to $21 / 2$ feet apart and 10 inches in the rows are the distances mentioned; the experience of our growers being evidently to the effect that those distances are altogether too close to suit our conditions.

SoIL AND Location.

Michigan Bulletin, No. 143.

As a rule, the lighter sandy loams should be aroided, us the crop will be likely to suffer from lack of water, while the stiff clays can seldom be properly worked in the spring, and if neglected are likely to bake so that the plants suffer more from the lack of water than upon the lighter sands. In a general way, then, it will be seen that the heavier sandy loams and the lighter clay loams are best adapted for this crop, although good results will be obtained upon the lighter soils, if moisture can be provided. Fair returns are often obtained upon a soil of a mucky nature, as the water is generally so near the surface that droughts will have no effect; but two difficulties are frequently met with upon this class of soils, the first being the danger of frosts while the plants are in blossom, and the other that the plants make a rank growth and fail to form the necessary fruit buds. Where the mucky soil is in a basin, entirely or nearly surrounded by higher lind, the blossoms seldom escape the frost, but if situated so that the cold air can drain off upon a lake, or still lower land, the danger will be lessened.

\section{(Central Experimental Farm Bulletin No. 5.)}

Any soil that will produce a good crop of potatoes or other vegetables will answer for strawberries. It should be well drained, either naturally or by tile drains. A rich clay loam is preferable, and will usually give the largest yield, but the fruit will not ripen as early as on sandy loam. Avoid, if 
possible, a stiff, heary clay. While a clay loam will give the best results if properly managed, it will not prove satisfactory unless it is well drained and the soil thoroughly prepared in the autumn previous to planting.

\section{Preparation of the Soll.}

For profitable growing on a large scale, select a piece of well-drained clay loam. This should receive a heavy coating of maure in the spring and then be either summer-fallowed or planted with potatoes, vegetables, or some other early crop which can be removed in time to permit of a proper preparation of the land in autumn before it becomes too wet with fall rains. A subsoiler should follow the common plough, one that will stir up the sub-soil to the depth of $\bar{j}$ to 10 inclies without bringing any of it to the top. Subsoiling is not absolutely necessary, but land thus loosened up will retain moisture longer in time of drought and dry off much more rapidly after heary rains. The last ploughing in the fall should be thoroughly done and suitable furrows provided, so that all surface water may run off quickly. Early in the spring, as soon as the weather and the condition of the soil will permit, cultivate deeply, both lengthwise and crosswise, with a two-horse cultivator; harrow down smooth and the land will be ready for planting. Aroid plowing a heary soil in the spring for immediate planting.

Gravelly or sandy loam should be heavily manured in the spring, and may be planted with regetables. All weeds should be kept down during the summer. Plough in the fall and again in the following spring, and harrow thoroughly. No subsequent tillage will make up for inadequate preparation of the soil for strawberry culture. A stiff clay loam is more difficult to nıanage. A crop of clover or other green manure turned under will help to make the soil more friable. Coarse barnyard manure should also be used whenerer it can be applied in time to decompose and become well mixed with the soil before planting. Tile drains in such soil require to be much nearer together and should not be too deep, usually not more than two and a half feet. In the autumn, before the land becomes too wet, trench it up in high, narrow ridges; if done with the plough, turn two furrows together, forming a sharp ridge, as when prepared for carrots or other roots. Surface drains should be made to take off surplus water quickly. Wlien thus exposed to the action of the frost, a comparatively heavy soil will work down fine and mellow in the spring and give good results. Care must be taken, lowever, never to stir such soil when wet, either with hoe, plough or cultivator.

\section{(Michigan Bulletin No. 163.)}

To precede the strawberries, a heavy clover sod is desirable, as this can be turned under and will not only provide a large amount or plant food, but it will so add to the humus in the soil that there will be far less danger from drought

Sod land is not desirable, as it is generally deficient in humus and plant food and frequently contains insect larvæ, which may prove destructive to the plants. Almost any of the hoed crops may be used for one year previous to setting the plants and will leave the land in good condition for the strawberries, especially if it was heavily top-dressed with stable manure in the 
spring, or fall previous to planting. Few soils will give the best results without the use of manure or fertiliser of some kind, and if the manure can be applied to the land at least once a year before it is to be used for the strawberries, it will decompose and will be in a suitable condition to yield up this plant food.

\section{Plants.}

All strawberry-growers are aware that it is only the plants formed by the runners that should be used for the new plantation; these have yellowish white roots, and can thus be distinguished from the other plants, which have a long stem, at the lower end of which are black or brow'n roots, many of which are dead or broken. If plants of good quality, which can be depended upon to give large crops, are desired, those selected for planting should have good crowns and well developed roots. As a rule, only the first plants on the runners should be used. When the plants are allowed to layer freely, a large number of weak sets are produced, and although these will grow they give a small yield, and the practice, if persisted in, will result in the running out of the variety.

The best plants can be secured from fields that have been grown but one year, and which have not as yet fruited. The practice of obtaining plants from old plantations, although used by many persons, is not a good one, as continued fruiting cannot fail to sap the vitality of the plants and the runners produced by them will not give as good results as those from young plants. Whatever method of digging the plants is used, whether by spade, fork or potato hook, care should be taken that they are not exposed to the drying action of the sun or wind, and as soon as dug they should be placed in baskets, boxes or bags, and after being moistened should he put where they can be kept fresh and prevented from wilting.

\section{Planting.}

Where the plants are being set, equal care should bc taken that the roots are not exposed. If the soil has been so worked that a dust mulch has been provided, the soil that will be in contact with the roots will ordinarily have a sufficient amount of moisture, and watering will not he necessary, but should the soil be dry, a pint or so of water should be given each plant before the planting has been completed; this will permit of the drawing of soil about it after the water has soaked in, and the baking of the soil about the plant, which otherwise might happen, will be prevented. In setting the plants, a spade, dibble or trowel may be used, and if the work is properly done there will be little difference in the result secured. When the dibble or spade is used, a cut is made in the ground to the depth of 6 to $S$ inches. and the soil is pressed back in either direction by a side movement of the handle; in the opening thus formed the roots are placed, care being takeu that they are not cramped and that they are so spread out that the soil can be brought in contact with each of them. When large plants, with a thick mat of roots, are used, this is particularly necessary, as otherwise the soil would only be in contact with a layer of roots upon the outside of this bundle and the inner roots will become dry and the plant will wilt. There is also considerable danger of loss if attention is not given to the depth at which 
the plants are set; they should be at such a depth that the bud will be just above the surface, as, if deeper than this, there will be danger that, especially on heavy soil, the bud cannot make its way through the soil; while if not deep enough, a part of the roots will be exposed and the plant will be very likely to dry out. If placed perhaps a quarter or half-inch deeper than it grows in the field, this will be sufficient to allow for settling of the plant and will leave it in about the right position.

\section{(Central Experimental Farm Bulletin No. 5.)}

After the land has been well prepared, mark off with a corn marker, or stretch a line to plant by. Take pains to have the rows straight; it adds to the appearance of the plot and time is also saved in the cultivation. Trim off all dead leares and old runners from the plants; shorten the roots to three or four inches; keep them moist and where the wind camnot reach them while out of the ground. When planting, make a hole deep enough to admit the roots without doubling them up. Take the plant in the left hand, place the crown on a level with the surrounding soil, spread the roots out fanshaped, fill in the soil, working it in among them, and press so firmly that by giving a quick jerk on a leaf it will break off without moving the plant. Only plants of the previous year's growth should be used.

Figure 1 shows the correct way of setting the plant. In Figure 2 the roots are all in a bunch, instead of being spread ont erenly as in Figure 1. They cannot, therefore, make such a vigorous growth. When planted too deep, as in Figure 3, they are nearly always smothered and will rot off at the crown. In Figurc 4 the crown is above the level of the surrounding soil and, therefore, too high. When thus planted, they generally wither and die in a few days.

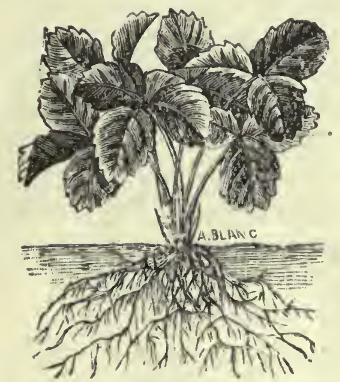

Fig. 1.

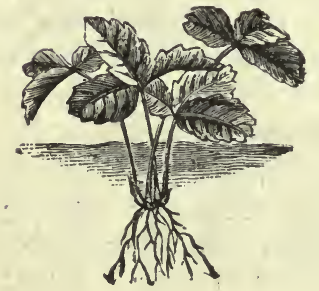

Fig. 3.

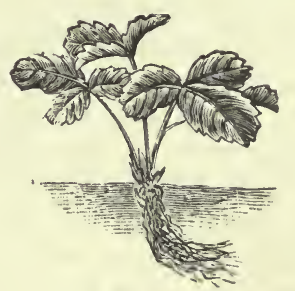

Fig. 2.

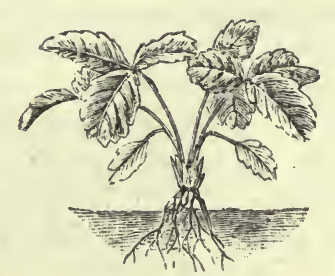

Fig. 4. 
Several different systems of planting have been practised successfully. The method of planting should be regulated by the quantity of land to be used, the amount of labour and manure at the disposal of the planter, the varieties to be planted, whether for market or for a city garden, or on the farm for family use.

Hrlu Systear.-For a city garden, where land is usually scarce, the hill system will generally give very satisfactory results. Plant in rows 2 feet apart and 12 to 15 inches apart in the row. Cut off all runners before they have time to take root, thus enabling the plants to make strong stools or hills by the end of the growing season. Any blossoms which appear the same season of planting should be removed. In an unfavourable locality, where much alternate freezing and thawing is likely to occur during the winter and early spring, growing in hills is not always successful, as they are more likely to heave with the frost, and the plants do not afford the same protection to each other as when planted in matted rows.

Matted Rows. - For this mode of culture, the rows require to be from $21 \%$ to 4 feet apart, and the plants 12 to 15 inches apart in the row. Cut off any blossoms which may appear, also the first rumers, until the plants have gained sufficient vigour to send out sereral strong runners at once, when they should be allowed to take root and form a matted row from 6 to 12 inches in width. All free-growing sorts make too many plants and should have all surplus runners cut off. The plants should not be crowded in the row. From 3 to 6 inches apart each way will gire the required protection to each other and room to produce fruit of large size and in abundance.

\section{Cultivation.}

\section{(Michigan Bulletin No. 163.)}

The ideal method of cultivating strawberries is to have the land at all times in about the condition it would be if worked with a garden rake, and this can only be secured when tools with narrow teeth are used. If the soil is inclined to bake, it will often be advisable to break the crust that forms about the plants after a rain, and during the season it should not be neglected whenever necessary, to keep down the weeds and prevent the formation of a crust. As a substitute for the hoe, a light potato hook is recommended, as this can be used to work closely about the plants without danger of injuring them, and will leave the surface in better condition than the hoe.

During the first season the plants should not be allowed to bear fruit, and as soon as the blossom stalks are large enough to permit of its being done readily, they should be broken or cut out. When the plants start to form layers in large numbers early in the season, it will be advisable to remove them. This may be done with a hoe, or with some of the cutters made. for the purpose.

\section{(Central Experimental Farm Bulletin No. 5.)}

Nearly all soils are full of weed seeds. When these germinate and appear above ground, cultivation should begin. Frequent stirring of the soil will destroy these weeds, and during drought will cause sufficient moisture to be retained in the soil to enable the plants to make a strong growth. 
Never allow weeds to grow in the strawberry patch. Cultivate carefully and thoroughly. By runniug the cultivator the same way every time, the plants that are newly rooted will not be so readily disturbed. Care must be taken not to stir the soil immediately around the plants, especially early in the season, as this is often the cause of their making feeble growth.

\section{(New Zealand Bulletin No. 46.)}

In order to be successful in strawberry growing, four essentials are necessary, namely, good plants, good drainage, deep culture, and heavy manuring. When these are properly combined the plants soon become established, sending their roots deeply down in search of food and moisture. Thorough preparation of the land before planting is of paramount importance. Drain where necessary, then bastard-trench, or plough and subsoilplough, working in manure at the same time. All growers consider stable manure the best where arailable, but where artificial fertilisers are appilect they must be such as will induce healthy, vigorous growth, and at the sume time are rich in potash. It may be said of the strawberry, the heavier the dressing of manure applied the hearier the crop, and the longer the plants will remain in a healthy bearing condition.

\section{Fertilising the Soll.}

\section{(Brother Jonathan Serics, No. 3.)}

It is of the greatest importance that the soil be rich if profitable results are expected in strawberry growing. One of the most economical methods of getting the soil in good condition is by means of growing and turning under green leguminous crops, crops of the pea, bean and clover family. This means that the grower must begin the preparation of his land several seasons before the berries are to be grown. It is cheaper to get the soil rich and also mellow by this means than by the exclusire use of fertilisers of any other kind.

Clover is one of the best plants to grow for this purpose in soils where a good stand of clover can be secured. It should be allowed to occupy the ground two years and then the stubble should be turned under. The clover roots deeply, and thereby mellows the soil and airs it out to a good depth. It also brings up fertilisers from lower down than most field crops grow. Much of this fertility is left near the surface of the soil when the stubble is turned under. The greatest value of the clover, however, lies in its ability to get its nitrogen from the air. Nitrogen is the most expensive fertilising element to secure, if purchased as a fertiliser, and it is the most difficult to hold in the soil. The clover gets it free from the air and adds it to the soil when its roots and stubble are ploughed.

Where clorer will not do well, or where one can wait only one season to get the soil ready, some other crop of the same family, which will finish its growth in a year, may be used. Toward the south the cow pea is one of the best. This plant will thrive on soil so worn that a stand of clover cannot be secured. It gets its nitrogen from thie air the same as clover and it also mellows the soil, leaving it in fine condition to be worked. In the north the Canada field pea is sometimes used. Peas will enrich the soil more if the whole crop is turned under after it has fully gotten its growth. It is sometimes wise, however, to cut the crop for hay or pasture it and turn under only the stubble. 
Barnyard manure is one of the best fertilisers, where it can be obtained in sufficient quantity. It is a complete fertiliser, supplying all the necessary elements of plant growth. Aside from this, it renders the soil mellow and spongy, making it more easily worked and less subject to injury from drought. Manure may be applied for strawberries in large quantities where it can be had. Twenty to fifty tons to the acre is nome too much for ordinary soils.

Where the soil is rich but heary and subject to bake, it may be mellowed by turning, under other green: crops. Rye or winter wheat are good. Thes may be sown in the fall and turned under in the spring, after they have made considerable growth. Grass sod ploughed under and allowed to rot usually leaves the ground in good condition for strawberries.

Wherever sod of any kind or green crops are turned under, the soil usually should.be cultivated for a season or two to hoed crops before planting to strawberries, in order to rid the field of the white grub, one of the serious insect pests of the strawberry. The white grub usually infests soddy soil, but disappears when the soil is given clean cultivation for a season or two.

Wood ashes, when obtainable, are a good fertiliser for strawberries. They contain large quantities of potash, one of the essential forms of plant food required by the strawberry. They should be sowed thinly over the land and harrowed in while the soil is being prepared for setting the plants. They may also be applied to the old bed at the time it is being renewed and worked in between the rows.

On thin soils commercial fertilisers are sometimes used. The three principal plant food ingredients needed are nitrogen, phosphoric acid and potash. The amount of each of these which should be applied differs in different soils. Some soils may lack only one of these essential ingredients; some may lack two of them. If the soil is generally poor, it is likely to lack all three. The safest way to determine which to apply is to try it on each soil. The chief source of nitrogen in commercial fertilisers is nitrate of soda and sulphate of ammonia. Either of these may be applied at the rate of from fifty to one humdred pounds per acre. Potash is secured in sulphate of jotash, muriate of potash or kainit. The two former may be applied at the rate of fifty to one hundred pounds per acre, and the latter in much larger quantity. Phosphoric acid is usually purchased in the form or acid phosphate or in bone meal or dissolved bone. 'Two hundred pounds of either of these may usually be applied per acre.

The following is a copy of the questions which were sent out to some of the provincial growers:-

Will you be good enough to give me your opinion as to the best variety of strawberry to cultivate-

(a.) For home use to ensure a succession?

(b.) ,, local market?

(c.) , shipping?

What time of the year do you recommend for planting?

What system do you recommend-matted row; or hill system?

What method of cultivation do you recommend? 
Do you recommend mulching? If so, at what seasoll-tVith whst material, and method?

The gist of the answers here follows:-

George R. Lawes, Enderby: Have had no experience with berries ror home tise or local market. The Magoon and Campbell, with me, brat the largest number of big berries and are the best for shipping. I larc tried perhaps fifty other rarieties and am hoeing them all out. The Campbell bears a light crop of grand berries of large size and quality, late to vary late.

A. E. Gale. Victoria: I find the Improred Sharpless does best with me, either for home use or local market, but for shipping, the Magoon is the best we have tried so far. We plant in the fall, in Oetober, if the ground is well drained, or in the spring, in April, as soon as the ground is dry "rough to work. We plant in rows 3 feet apart and 15 inches apart in the row. Keep all rumners cut off and pick off all bloom from spring planting. If keep horse cultivator going at frequent intervals to destroy weeds and retain moisture. Yes. I certainly recommend mulching during the fruiting se:ison; any kind of straw will do, but I prefer clean oat straw. We always put it on from three to ten days before the first berries are ripe. With an average crop the local market is entirely overdone. It would not be wise to encourage planting anytling but shipping varieties.

George Every-Clayton, Burnaby: Your first question re strawberry culture is dependant entirely on local conditions of climate and soil, and can only be answered by a practical test, but should recommend (a) Jocunda or Magoon, (b) Magoon, (c) Clarke's Seedling or Paxton. Have not as yet found a strawberry appreciably earlier than the Jocunda that was worth cultivating. I recommend planting during April, early in the month if season permits. I prefer the hill system of cultivation, planting in rovs 3 feet apart, plants 15 inches apart (at least) in row. Keep all blossoms and runners cut off first year and cultivate with horse often enough to keep down weeds and prevent soil packing. Have had no experience of mulching, having excellent results without.

Andrew Strachan, Victoria: As to my opinion of the best varieties of strawberries and methods of culture for this locality, I may say that, after experimenting with many varieties, the most suitable for this locality are: (a.) For home use, the Improved Sharpless; (b.) For local market, Improved Sharpless. It gives a large crop of berries of fine quality and carries its size well througl the season. (c.) Shipping; so far the Magoon has proved the most productive of the varieties tested and also given the best satisfaction in distant markets. (d.) The Paxton has also been shipped this year with fairly satisfactory results, but, in my opinion, it is more suited for the local market. I liave had the best results from planting in the spring, as early as the ground is in suitable coudition, in rows 3 feet apart and plants 18 inches apart in the row. Give clean cultivation and frequent, with a view to conservation of moisture, especially after rain, to prevent the surface getting caked. I have not experimented with mulching further than straw between rows before picking commences, to keep the berries clean; this I put on about two weeks before picking commences, and carefully place under fruit and between rows. 
J. C. Metcalfe, Hammond: In-reply to yours re inquiry as to strawberries, may say that I recommend Excelsior, Warfield, Magoon, for home use and local market, and Wilson for shipping. I recommend spring for planting, narrow hedge row for light soils and varieties that do not make runners abundantly; hill system for heary soil and rarieties that make runners abundantly; shallow, frequent and clean cultivation up to within two weeks of picking fruit. Yes, I recommend mulching in Norember with first frost, with meadow hay cut early, or straw. Mulch should be taken off as early in spring as possible; then put back under the plants and between rows after last cultivation.

W. C. Grant, Gordon Head: After ten years' experinental work with strawberries and covering some 250 varieties, we have discarded all except Sharpless for local market and Magoon for shipping. If confined to one variety, would select Magoon; it is the variety that is to bring fame yet unknown to Southern Vancouver Island growers. Under proper conditions of handling, this variety will stand up in perfect condition ror a period of nine to ten days; it far excels the Clarke's Seedling or the famous Hood River berry, as tested here. Fall planting has been tried two different seasons, with exactly the same results. We have come to the conclusion, speaking from a commercial standpoint, fall planting is not u paying proposition. Spring planting has always given satisfactory results. The hill system is the only practical method of growing strawberries successfully in our climate, owing to the dense growth of weeds during the winter months. By following the hill system we can hoe during January and February when weeds are starting ont rapidly, especially from the 15th February to the 1st March. We plant rows $3 \mathrm{ft}$. $6 \mathrm{in}$. apart, plants stand in row $1 \mathrm{ft}$. $6 \mathrm{in}$. apart. Cultivate with 12-tooth Planet Junior horse cultivator and pulveriser combined, rumning the cultivator every week to ten days where the land is in condition up to the time of putting on the mulch, running the cultivator from one inch to one and one-half inches deep. After crop is harvested, run cultivator once or twice full depth to break up the crust that has been formed by the repeated tramping of the pickers. Mulch with oat or wheat straw when the first berries are about the size of peas; if done at this time all the fruit stems are standing up and the straw can be spread between the plants and no lifting of fruit stems is necessary. Pick the beds daily, removing all berries that show signs of colour. When the bed is properly picked, every remaining berry is green; if a trace of colour is showing, the work is not thoroughly done, and under good weather conditions any berry left on the vines with slight colour will be over-ripe by next picking. By this method the berries will reach the distant markets in prime condition and will colour up thoroughly, provided care has been exercised in picking and cooling the fruit off, etc. Cooling the fruit is of great importance, and must be attended to if satisfactory results are to follow. Place in a cool place over-night one crate deep with $2 \times 4$ scantling below each end of crates, and turn lid of crate with cleats down on top of crate; in the morning nail the tops on crate, and deliver for shipping early before the heat of the day has advanced. If handled this way and the berries kept in a cool place constantly, Magoons will be in good condition nine days from time of picking. 
W. T. Hayhurst, Armstrong: As to the best variety of strawberry to cultivate, I give the following as my experience: Clyde is the earliest with me; it is a heary cropper, good for home use and local market, but a poor shipper. Magoon comes next; it is a fine berry, either for home use or local market, or for shipping, a good cropper, the best all-round berry with me. Clarke's Seedling is good for home use, local market, a splendid shipper; it is not as rank a grower as Magoon and not quite so productive, but a very attractive berry. Nick Ohmer is a perfect berry and productive, but the plants seem to kill out very bad with me. About one-third died the first winter. I have several other varieties growing here now. Some I have not tested enough to give any opinion on; the ones I have mentiuned are the best I have tested so far. I have had very good success planting in October; the plants get rooted in the fall and make far better growth during the following summer. They should not be allowed to bear fruit the first summer. I like the hill system the best; the plants will bear two more good crops of fruit than by the matted row system. Besides, I think there are quite a lot of berries destroyed by the pickers when they are matted. I find that cultivating them thoroughly in spring until they come in blossom is the best plan; also as soon as the crop is off until fall, with horse cultivator. I do not think strawberries should be grown here without mulching; the weather is showery during the fruiting season, and if they are not mulched the berries are spoilt by sand. I think that wheat straw cut with a chaff cutter makes the best mulch : as it does not interfere with cultivaion after the crop is harvested. Mulching can be done when they are coming into blossom. It is easily done with cut straw. Fill a large basket and scatter along the plants; the chaff will fall in and around the plants throughly. I do not like the mowing off the plants and burning them. It might be a good plan in some localities, but $I$ think the sun is too hot here for that. When the tops of the plants are mowed off the sun is too hot for the exposed roots, and seems to kill a good many of them.

Thos. A. Brydon, Victoria: The Magoon is the berry that I am growing almost exclusively, and especially for shipping. It is a number one berry. I recommend spring-time, as early as the ground can be got in good condition, for planting. The hill system I recommend. Mulching should be done just before the fruit begins to ripen, covering the whole ground and under leaves of the plants with straw, but before the mulch is placed be sure the ground is well cultivated and all weeds removed round the plants. Clean cultivation is an absolute necessity to success.

W. H. Lewis, Burnaby: I grow nothing but the Magoon now. I used to try and grow berries to give a succession, but gave it up. Late frosts killed the bloom on early varieties most of the time. Mitchel's Early was the best I ever tried for early crop and Gandy for late, but Gandy is a poor cropper. This market demands a large berry and Magoon fills the bill as well as any; it is a good cropper and fairly good shipper. I advise planting as early in the spring as it is possible to get the ground in good shape. Never plant in the fall. Hill system, not over 10 or 12 inches apart by about 32-inch rows. I used to plant a great deal farther apart, both ways, but am convinced it is a waste of ground. Keep clean and cultivate with Planet Jr. cultivator about once a week from early spring until blossoms 
appear, has been my rule heretofore, but the best crop of berries I ever grew were mulched in the fall and taken off in the spring, when I cultivated as before mentioned. I decided two years ago that I would never grow another crop of berries without fall mulching, because the plants invariably freeze with the frost to a greater or less extent and damage the plants accordingly. However, I never carried the resolution out and am sorry for it, because if I had done so I am satisfied I would have had a bumper crop this year, instead of nearly a failure from freezing of the plants last winter.* There is not much choice of material; straw is about the only material available, but the straw we get here carries a great many weed seeds, especially thistles. If I was to grow my own straw it would be rye. I shall leave straw on my two acres all next winter. I never had any success with pistillate rarieties. Have tried several. Seem better adapted to dry climate. They gire lots of bloom, but wet or damp weather seems to prevent pollination of the blossoms and they drop off. I should never burn off the straw on a patch of berries as advised by some. Might possibly do on bottom or wet land, but it does harm on high, dry land to the plants; and I do not believe in burning ansthing I can put in the ground in the shape of humus. It is my belief that good berry land has been run out in this district by this method of mowing and burning the tops and straw, thereby robbing the soil of all the humus. Besides, the method is of no value to eradicate the strawberry weevil, as proved by myself and others that I have watched. By cultivation and rotation with potatoes I liave routed the weevil off my place. I think mention of the soil is necessary to be of any information to others. Mine is high land, fairly good sand loam, with but little clay. I have been growing berries 12 rears.

Samuel Smith, Armstrong: I think the Magoon is the best for shipping. For other uses I am not posted. I think the spring is the best time to plant, and $I$ think the hill system is the best. I cultivate, with a one-horse cultivator. I would certainly recommend mulching; short straw seems to me the best material.

L. Claude Hill, Burnaby: I find that location has a great deal to do with success in strawberry culture. Varieties that have done well with growers in Hammond and Haney have not been a success with us. It has taken us years of experiment to find plants suitable to this location and soil. For home use we like Sharpless and Jocunda; for local market, Magoon and Sharpless. We have not shipped many berries, but find that Magoon ships fairly well. The hill system suits this location, as we cater to the local trade and want large, fine-looking fruit. For cultivation we use Planet Junior horse cultivator, both 5 and 13-tooth kinds; rows 3 feet apart and plants 15 inches in the rows. All runners and blossoms are cut off the young plants the first season. Mulching is put down just before the fruit forms and is only used to keep the berries clean. We do not use any winter mulch. We find two tons of straw to the acre about right. After the crops are picked the plants are all cut down and the straw fired, leaving the patch after the burning without a green leaf and with very few weeds. The fire also destroys leaf blight and injurious insects. Cultivation then commences again. We use baled straw for mulching, which has to be put down by hand to ensure *1904. 
getting it well round the plants and under the fruit. We are always wanting new varieties and would be glad to get any samples that are being tried at the Experimental Farms. I might mention that Magoons and Sharpless have been grown here on high land, alder bottom and peat soil, with very. good results.

A wholesale dealer in Victoria gives the following as his experience:-

"The Magoon is far and away the best all-round strawberry. Clarke's Seedling is equally good, better in some respects, but it is a poor cropper. It is the berry grown at IIood River, Oregon. Sharpless is altogether condemned. It is a fine large berry, but does not hold up at all."

\section{Moisture aNd IRRIGation.}

(Michigan Bulletin No. 163.)

There are few locations where strawberries are not each year more or less injured by lack of moisture in the soil, and where water can be readily secured for irrigating purposes the expense of applying it will be well repaid. Oftentimes a single application made when the fruit is about one-half grown will double the yield, and occasionally a crop will be saved which would be otherwise lost. Although its use is of less value during the first season's growth, it will often be found desirable, when the weather is dry, to make an application in order to promote the growth of the plants.

Sub-IRRigation.-By placing a line of drain-tile below the surface, a strip from 10 to 20 feet can be watered. If it be left permanently, the line should at least be below the reach of the plow; and in case the land requires underdraining, the tiles may be so arranged as to answer for both purposes. The depth should be then not less than $2 \frac{1}{2}$ feet, and the tiles should be laid as nearly level as possible, and yet give a fall towards the outlet. When required for irrigation, the lower end of the tile can be closed and the drains flooded from the highest point. If merely needed for the strawberry crop, a temporary system of tiles may be laid. If put in before the plants are set, they should be covered at least 4 or 5 inches to be below the reach of the cultivator, but oftentimes the necessity is not recognised until about the time the fruit is ripening, and then it will be sufficient if the tiles are barely covered. Care should be taken to have the lines of the tile practically level for lengths of less than 100 feet, and beyond this the slope should be very slight. Where the tiles have a greater slope the water rushes to the lower end and breaks through to the surface. When properly arranged, the water should enter the tile only as fast as it soaks through the joints. In this way the tiles will be kept full and the water will be very equally distributed throughout the length of the tiles. While smaller or larger sizes might be used, a 3-inch common drain tile will give the best results. As most tiles are slightly curved in burning, by placing them with their rounded sides uppermost, a small crack will be left on the under side of each joint, and if care is taken that these openings are of about the same size, the water will be very evenly distributed. When the plants are set in narrow beds, a single line of tile along the centre will sufflce, but the best results will be secured if the lines are independent, and each is filled from the highest point. A very small stream of water through a garden hose will supply a line 100 to 
200 feet in length, and after having adjusted the flow, it will require no attention until the ground has been thoroughly wet. As the water will be applied beneath the surface, there will be much less loss from evaporation than when furrows are used, and, consequently, it will be more economical of water, and will permit the covering of a considerable area through a small supply pipe with but little attention. Under the same conditions, the use of furrows would not give nearly as even distribution and would require constant attention.

\section{Frost.}

(New York Experimental Station Bulletin No. 12\%-128.)

Although frost is continually showing freaks, the injury that is done to blossoms can be greatly lessened if proper care is taken to secure a location with thorough air drainage, which can be best obtained on an elevated rolling site. While this is quite essential in the interior, less attention need be paid to it near the lake shores and along the rivers. When air is well charged with vapour the injury from frost is greatly reduced, and where water is available a crop often can be saved, which would otherwise be destroyed, by sprinkling the plants just at night, or, better yet, very early in the morning, when the temperature drops to 32 degrees. With a supply of hose and an ordinary lawn sprinkler a considerable area can be covered.

\section{Pollination.}

When strawberries are grown in matted rows, each third row should be planted to a staminate, or perfect-flowered variety, to provide for pollination of the flowers, care being taken to plant near together varietites which bloom at the same time. This plan of setting the perfect flowered and pistillate, or imperfect flowered varieties, in separate rows, rather than distributing the staminate plants in the rows of pistillate varieties, is preferred, as it facilitates separate picking and marketing of the varieties-a very important factor in securing ready market and good prices for the berries.

\section{(Central Experimental Farm Bulletin No. 5.)}

Strawberry blossoms are divided into classes, 1st, bi-sexual or perfect. These contain stamens or male organs and pistils or female organs, as in Figure 5, hence are called perfect or bi-sexual. Second, pistillate or imperfect, which contain pistils only, or female organs, as in Figure 6. Pistillate

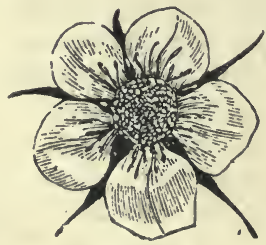

Fig. 5 .

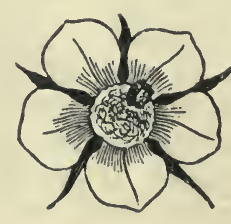

Fig. 6 .

varieties usually yield the largest crops of fruit when properly fertilised. This may be done by planting one or two more rows of a perfect-flowering sort to every four or five rows of those with imperfect blossoms. 
Picking and Packing.

There could be volumes written on this one question of picking, but I will touch it lightly. Have everything ready before time to commence picking. Don't think of hauling your berries in a waggon without springs. Use no dirty packages to ship in. Have your erates and trays, or carriers, ready. Make those during the winter while you are resting. Don't allow more than four boxes to be taken out in a tray, as it keeps berries exposed too long to the hot sun. Try to grade berries in the field, if they need grading. Every time you tonch a berry you damage it. Fill boxes well when packing in crates. Pick every day that is fit after the season is fairly started; if you wait one day and it rains the next, you may not get your field cleaned up well again during the season, and will always have more or less soft berries.

Finally, in reference to strawberry-growing, as there is considerable labour and expense attached to the work, it should be the aim of the grower to produce heavy crops from a limited area. If more attention at the first were given to properly preparing the land before planting, more care bestowed in the cultivation of healthy, virorous plants, free from disease, and a liberal supply of fertilisers afterwards used, more varieties and better strawberries could be grown, much heavier crops produced, the season prolonged, and the demand increased.

Like most other fruit, the varieties that have been sent out from time to time are legion; still, those suited for profiable culture are limited in number.

The following information is.supplied by Mr. A. E. Gale and Mr. Thos. A. Brydon, growers in Victoria District:-

"The first thing one requires to get fixed in his mind is that the less the berries are handled the better for them; they should be nipped (not pulled) with the thumb or finger nail, leaving about half an inch of the stem on the berry. Do not hold the berries in the hand until it is full, but put each berry in the box as soon as it is picked, for the heat of the hand quickly spoils its freshness and makes the berries soft. In order that the fruit may reach the market in the best condition, it should be taken in out of the hot sun as soon as possible and placed in a cellar or other cool place for a few hours before being shipped. Fruit that is thoroughly cooled will hold up at least two days longer. Never pick whilst the berries are wet with dew or rain.

"The great demand that has sprung up during the last few years for shipping berries, and the increased acreage that has been planted, renders it imperative that every grower should pick as much as possible for shipping; it is absolutely necessary to do so to avoid a glut on the local market. For shiping to the North-West the berries must be picked as soon as they show light red on one side; if they show colour all over they are too ripe for shipping, and must be sold on the local market, regardless of price.

"The boxes are regulated by a Dominion Government law in two sizes, viz., 4-5ths of quart and 2-5ths of quart, the former being 2 inches deep and $51 / 4$ inches square, and holds about 1 tb. 2 oz., the fruit being sold by measure. not by weight. The crate holds 24 boxes of the larger size, and can be pur- 
chased from local box manufacturers at about 25 cents, cornplete with boxes.

"The veneer for making the boxes is manufactured exclusively by the B. C. Manufacturing Co., New Westminster, B. C., and costs this year $\$ 3.25$ per $\mathbf{M}$. in the $K$. D. (that is not made up) f. o. b., New Westminster. The crates can be bought for $9 \frac{1 / 2}{2}$ cents each in the $\mathbf{K}$. D."

\section{DISEASES.}

\section{(Michigan Bulletin No. 163.)}

Strawberry Leaf Blight (Sphoerella fragarioe-Sace).-While subject to the attack of but few diseases, nearly all varieties of strawberries are more or less injured by the fungous disease commonly known as strawberry rust or leaf blight. This attacks not only the leaves, but the fruit stalks and the calyx, or husk, about the berries, and the injury is thell so severe that the rrop fails to ripen. It appears first as a purplish spot upon the leaves, but as this enlarges the centre becomes brown and finally white. If these spots are numerous upon the leaves, the tissue finally dries out and the entire leaf will be destroyed. The injury is even more severe when upon the fruit stems, as a very small spot will be sufficient to girdle them, and the shrivelling and drying of the fruit will follow.

There is a marked difference in the susceptibility of the different varieties to attack by this disease, and in selecting varieties for planting those that are least subject to attack should be chosen. Some of the kinds that when free from disease are very productive, become almost worthless when the conditious favour the development of the fungus. When grown under conditions that favour a normal growth, and when they are not subjected to a check, even the kinds that are most subject to injury frequently escape. Experiments have frequently shown that all varieties can be kept practically free from the attack of this disease if properly sprayed with Bordeaux mixture. In setting out a new plantation, care should be takeu to obtain plauts that are practically free from disease, and all leaves that show signs of an attack should be removed and burned. As there may be spores of the disease upon the remaining leaves, it will be well to dip the plants into Bordeaux mixture, and after they have been set in the field, after a week or ten days, they should receive a spraying with the same material. One or two otler applications at intervals of two weeks will also be advisable, and still another should be made about the 1st of August, in case diseased leaves can be found at that time. The following spring the plants should be sprayed as soon as growth has started, and a second application should be made after the flower buds have formed, but before they open. As noted above, the use of Bordeaux mixture at this time will have a marked effect against the strawberry weevil, especially if Paris green is added. This treatment will ordinarily carry through the varieties that are most subject to the attack of leaf blight without serious injury. If the plantation is to be kept for another year, it will be well to burn it over, and to spray as soon as the new leaves have formed.

\section{(Central Experimental Farm Bulletin 21.)}

LAaf BufHT RUst.-The purplish or redish-brown spots which appear on the leaves of strawberry plants during the growing season and in greatest 
abundance just after midsummer, are the evidence of the presence of the above injurious fungous disease. The spots, at first small and few in number, increase in size till the entire leaf is involved, and the foliage shows the effect of a parasite's presence by shrivelling and withering. This loss of foliage is a very serious matter, often coming early enough to materially lessen the crop, and taking place at a time when the plant should be making new runners for the next rear. The fungus is carried over winter by means of spores and by means of mycelium (representing the vegetative portion of the parasite) contained within the leaves. Some varieties are affected much more than others. It has been generally noted that strawberries are affected to a greater extent on sandy soil than on clay loam.

Treatment.-Bordeaux mixture prevents this disease, and on plantations where the single crop system is followed this is the most practical and effective remedy. When two crops are taken from the plantation, mowing and burning the leaves on the rows immediately after the season of berry picking closes, is the practice in some localities.

MILDEw (Sphaerotheca Castagnei-Len.).-In dry seasons this fungus, which causes the leaves to curl, covering them with a thin, cobweb-like coating, lessens the crop very materially. Like gooseberry and grape mildew, the fruit is also attacked.

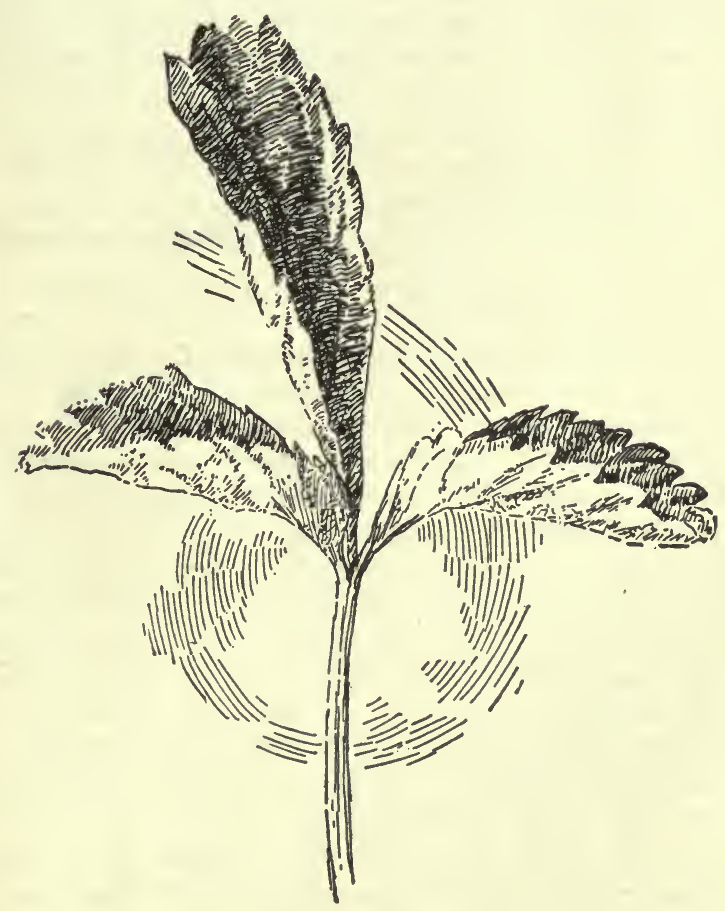

Fig 7. 
Remedies.-If Borleaux mixture is used in early spring as a rust preventive, this disease will also be clecked. If it appears to an injurions extent when the berries are ripening. flowr of sulphur may be used adrantageously. When this is scattered between the plants, the fumes given off muler the action of the sun's rays have a preventive action upon the growth of the fungus.

\section{INSECT PESTS.}

Black Vine Weevil (Otiorhynchus sulcatus-Fab.).-This beetle is probably the most destructive insect pest, both in its larval and perfect stages, on strawberries that we have in British Columbia. The mature insect is brownish-black, about half an inch in length, with the long snout characteristic of all weevils. The larva is a small white grub which attacks the crown of the roots and so kills the plant. Mr. Thos. Cunningliam, Inspector of Fruit Pests, recommends burning off the tops of the plants after the crop has been gathered. This has the effect of destroying the beetles, which shelter themselves amongst the leaves, and which they also attack. Dr. Fletcher says: "The only remedy which can be suggested for this beetle as yet is the planting of strawberries on new ground and frequent renewal of beds, the Worst injuries being done to the old plants." Mr. W. T. Macoun, the Horticulturist of the Central Experimental Farm, consider's the single crop method of growing strawberries the one which pays best, the fruit being finer and the land being kept clean much more easily. Some varieties which do not make rumers freely might be left for two years.

Western Tex-Lined June Bug (Polyphylla decemlincata).-The larva of this insect, which is a large white grub, is a bad pest on many plants, amongst which are strawberries. In its larval stage it attacks the roots of plants, very soon killing them, by stripping off the bark from the woody plants and biting off the root below the crown of strawberries and such plants.

Deschiption.-The perfect beetle, like its prototype the May Bug or June Bug or Dor Bug of the East (Lachnosterna fusc(l-Frolll), has a disagreeable habit of coming through open windows and buzzing about, knocking themselves against walls, ceilings and sometimes against one's face, which it strikes with considerable force. The beetle is about one inch and a quarter long, with a thick round body half an inch or nore in diameter, of a light brown colour, with eight white longitudinal stripes running the whole length of the wing covers and two short ones; the breast is covered with a brownish down, and the abdomen has three transverse stripes. The larva is about an inch and a half long, with a thick yellowish-white body and brown head.

Is in the case of the Black Vine Weevil, a frequent change of the bets is to be recommended, as being the most efficalcious remedy. It also resembles the last-named insect in its injurious habit, both in the larval and perfect stages. Naturally, on account of the nocturnal feeding habit of the beetle aud the underground liabits of the larva, it is a difficult insect to control. Referring to the Jume Bug, Saunders says:-

"It is very difficult to reach the larvae underground with any remedy other than digging for them and destroying them. Hogs are very fond of them, and when turned into places where grubs are abundant will root up the 
ground and devour them in immense quantities. They are likewise eaten by domestie fowls and insectivorous birds; erows, especially, are so partial to them that they will be often seen following the plough, so as to pick out these thoice morsels from the freshly turned furrow. Trees infested with the beetles should be shaken early in the morning, when the insects will fall and may be collected on sheets and killed by being thrown into scalding water. Besides the cherry and plum, these insects feed on the Lombardy poplar and the oaks On atcount of time the larva takes to nature, the beetles are not often abundant during two successive seasons."

Treat, another authority says :-

"As many insects are not injurious in their perfect form, the June Bu;" has not generally been regarded as harmful. $A \mathrm{~s}$ it is a destrutive feeder in its beetle state, it should be destroyed, not only for the mischief it may do as a beetle, but for the prevention of its progeny. Those that enter the house should be caught and killed.

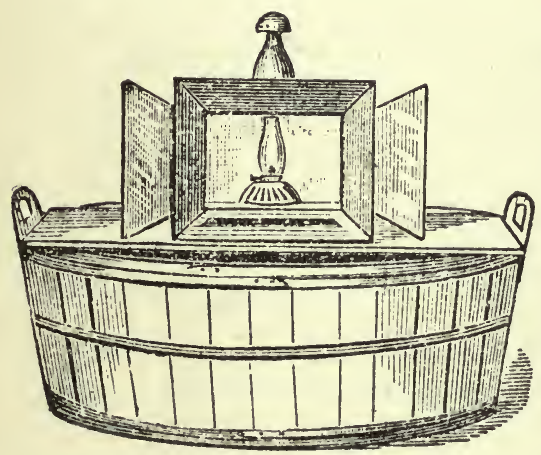

Fig. S. In each locality the insect is uswally more numerous than at other tin!es once in three years. When the trees in which they harbour are discovered, large numbers may be destroyed by placing sheets beneath the trees, and in early morning, when they are torpid, the beetles may be shaken from the trees, gathered and destroyed. As it is only in the perfect state that any effective war can be waged against the white grub, every method should be employed to kill as many beetles as possible. That which promises to be must effective is to

take advantage of the fact that they are attracted by light and to set teaps for them. A simple form is to place a lamp in a tub, made by sawing a barrel in half, in the bottom of which is a few inches of water. Several lanterns have been specially devised which, by throwing a strong light, will attract the beetle. That shown in the illustration (Fig. S.) is a French design, modified by a distinguished Ameriean horticulturist. It consists of a square glass lantern, at each side of which is a flaring tin reflector. $\Delta t$ the lower side of each reflector, near the glass, is a longitudinal opening. The lantern is set upon a cask or tub in which there is some water. The insects, attracted by the light, fly towards it, and striking the glass, fall downwards through the opening into the water. This has been found rery effective. It would be well, no doubt, to place upon the water a little kerosene, just a thin film, enough to cover each insect as it fell in."

The opinions given by the correspondents whose replies are published in the preceding pages, it may be remarked, whilst they differ slightly in some minor details, in the main agree very closely, except in the question of burning the tops of the strawberries after the crop has been taken off. On 
this point it will be observed that opposite opinions are expressed. It has unquestionably answered in some cases, and where it can be done with safety to the plants, there is no doubt but that many injurious insects, as well as germs of diseases are destroyed. Mr. W. A. Dashwood-Jones, New Westminster, who is a keen observer, writing on the subject of the strawberry weevil, says:- "I am still sure that fire is the best preventive; that is to say, burning up all the weeds and rubbish around the strawberry rows, including the foliage, after the crop is picked." It would seem that in localities where the sun does not exercise too much influence, the burning of the tops is beneficial; and on the other hand, in some localities, during periods of intense heat and drought, care at least should be exercised in the practice, if not altogether avoided.

\section{J. Ii. ANDERSON,}

Deputy Minister of Agriculture.

\section{Department of Agriculture,}

Victoria, B. C., April 25th, $190 \%$.

VICTORIA, B. C. :

Printed by Richard Wolfradex, I.S.O., V.D., Printer to the King's Most Excellen M 1907. 





\section{M259475}

$$
\begin{aligned}
& 5141 \\
& A 4 \\
& \text { ns.20-22 }
\end{aligned}
$$

THE UNIVERSITY OF CALIFORNIA LIBRARY 
